Fuss J., Voloboyeva A., Polovyj V., Yaremkevych R. The usage of antibiotic therapy for septic complications in colorectal surgery. Journal of Education, Health and Sport. 2021;11(12):235-240. eISSN 2391-8306. DOI http://dx.doi.org/10.12775/JEHS.2021.11.12.017

https://apcz.umk.pl/JEHS/article/view/JEHS.2021.11.12.017

https://zenodo.org/record/5790811

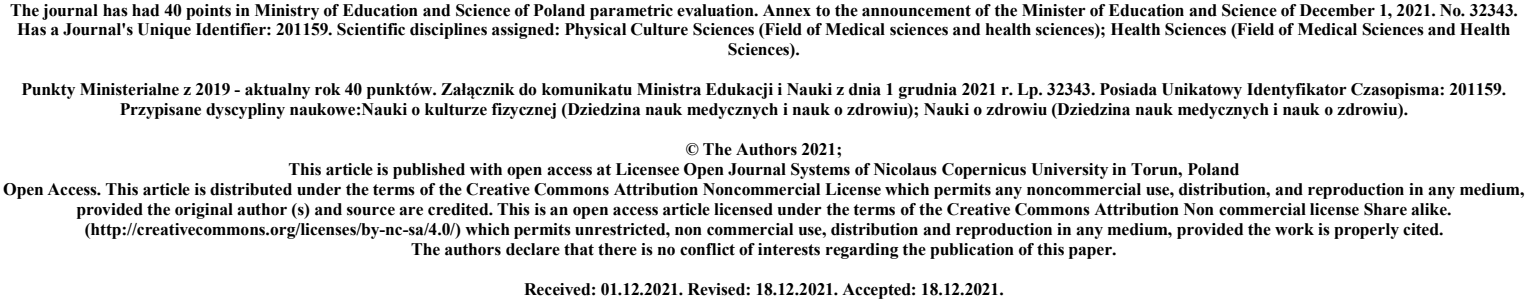

Received: 01.12.2021. Revised: 18.12.2021. Accepted: 18.12.2021.

\title{
The usage of antibiotic therapy for septic complications in colorectal surgery
}

\section{J. Fuss, A. Voloboyeva, V. Polovyj, R. Yaremkevych}

J.Fuss - Ph.D, general surgeon, department of surgery, Central Regional Hospital in Pustomyty, Lviv, Ukraine, e-mail: juliafuss78@gmail.com ORCID id: 0000-0003-01149475

A.Voloboyeva - anasteziologist, department of anesteziology, Communal Municipal Clinical Hospital 8

V.Polovyj - MD, Profesor, department of surgery, Bukovinian State Medical University

R.Yaremkevych - Ph.D, department of Surgery and Transplantology faculty of postgraduate education, Lviv State Medical University

\begin{abstract}
Over the past few decades, surgeons have made many attempts to reduce the incidence of surgical site infections (SSI) after elective colorectal surgery. Routine faecal diversion is no longer practiced in elective colonic surgery and mechanical bowel preparation is on the verge of being eliminated altogether. Intravenous antibiotics have become the standard of care as prophylaxis against SSI for elective colorectal operations. However, the role of antibiotics is still being debated.

The aim of the study was to reduce the proportion of antibiotic-resistant strains of pathogens of infectious complications in colorectal surgery by optimizing the use of antimicrobial drugs. Method: We analyzed data of 135 patients who were operated for colorectal cancer in our general surgery department in between 2019 and 2021. Age, gender, body mass index, presence of chronic pulmonary disease, surgery duration, disease location (colon or rectum), and surgeon volume were evaluated for associations with the development of superficial or deep surgical site infection.

Results: All parameters were found to be significant for the development surgical site infection except sex. Cut-off values were 63.5 years for age, 167.5 minutes for surgery duration.
\end{abstract}


Conclusion. The introduction of strict monitoring of compliance with the protocols of antibiotic prophylaxis and antibiotic therapy at the level of a separate surgical unit in a multidisciplinary hospital improves conditions for the rational use of antimicrobial drugs.

Key words: Colorectal surgery, antibiotic, treatment, prophylaxis, septic complication.

Introduction. Purulent-septic complications (PSC) in colorectal surgery occur more often than in operations on other organs of the abdominal cavity. The development of PSC significantly worsens the results of surgical treatment, lengthens the hospital stay, increase the cost of treatment and the risk of an unfavorable outcome [1,2]. Often there is a need to perform repeated interventions, which carry the same risks and complications as primary operations, thus closing a vicious circle. The main types of PSC that occur in patients with colorectal surgery are surgical site infections (SSI) [3].

The main etiological factors in the development of PSC are endogenous infection - microbial contamination of the surgical wound when opening the intestinal lumen, as well as microbial translocation of endogenous microflora. At the same time, it is not possible to completely avoid wound contamination even with ideal adherence to the rules of asepsis and antisepsis. By the time the surgery is completed, in $80-90 \%$ of cases, the wound is seeded with various microflora [4,5]. The main microorganisms causing PSC in surgical patients are gramnegative bacteria $(\mathrm{Gr}-)$, the most common of which are enterobacteria. In terms of antibiotic resistance, microorganisms of the ESKAPE group (vancomycin resistant Enterococcus faecium (vancomycin resistant Enterococcus - VRE), methicillin-resistant S. aureus (methicillin-resistant Staphylococcus aureus - MRSA), Klebsiella pneumoniae - CRK), Acinetobacter baumannii with multiple drug resistance (MDR), MDR Pseudomonas aeruginosa and Gr - ESBL producing enterobacteria [6].

An important link in the treatment of PSC is antibiotic therapy (ABT). Antibiotic therapy is not a substitute for surgical treatment and is often ineffective in the case of inadequate drainage of the site of infection [7,8]. However, an adequate and timely prescribed AMT, together with a fully performed surgical stage, can prevent further generalization of the infectious process and the development of multiple organ failure. Antibiotic therapy should be prescribed immediately when diagnosing PSC [9]. Late prescription of antibiotics significantly worsens the prognosis and increases the risk of poor outcome in patients with infectious complications. Considering that the identification of the pathogen and the determination of antibiotic sensitivity takes an average of 1.5-3 working days, the initial choice of antibiotic has to be done empirically[10].

The aim of the study was to reduce the proportion of antibiotic-resistant strains of pathogens of infectious complications in colorectal surgery by optimizing the use of antimicrobial drugs. Material and methods. Depending on the localization of the malignant neoplasm (MN), the scope of surgery included right-sided hemicolectomy, left-sided hemicolectomy, resection of the transverse colon, and resection of the sigmoid colon.

The study group (I) included 65 patients (mean age 79 years), the control group (II) - 70 patients (mean age 77 years). The ratio of men and women in the study group was $44 \%$ and $56 \%$, respectively, in the control group - $49 \%$ and $51 \%$, respectively.

Table 1 presents the basic data of the patients included in the study, demographic indicators, division of patients by urgency, the method of performing the operation and the nature of the main nosology. 
General characteristics of operated patients and performed surgical interventions

\begin{tabular}{|l|l|l|l|l|}
\hline Indicators & \multicolumn{3}{|l|}{ Group } & P-value \\
\hline & & I & II & \\
\hline Operation type & laporoscopic & 37 & 39 & 0,474 \\
\cline { 2 - 5 } & open & 28 & 31 & 0,895 \\
\hline \multirow{2}{*}{$\begin{array}{l}\text { Terms operations } \\
\text { of }\end{array}$} & urgent & 29 & 20 & 0,621 \\
\cline { 2 - 5 } $\begin{array}{l}\text { Character of } \\
\text { main nosology }\end{array}$ & Scheduled & 36 & 50 & \\
\cline { 2 - 5 } & Intestinal stoma & 23 & 35 & 0,756 \\
\cline { 2 - 5 } & Others & 37 & 32 & 0,612 \\
\hline
\end{tabular}

The comparison group (I) consisted of 65 patients, the median age was 65 (49-72.5) years, the main group (II) also included 70 patients with a median age of $67(57.5-71.5)$ years, $\mathrm{p}=$ 0.748 . The majority of patients in both groups underwent surgery for colon cancer - 23 $(17.1 \%)$ patients in group I and $35(26.7 \%)$ patients in group II, $p=0.6$. The proportion of laparoscopic and open surgery was approximately the same in both groups. Operations performed in a planned manner prevailed $(27 \%$ in group I and $37.7 \%$ in group II, $p=0.57)$. The groups were comparable in terms of age, gender, main nosology, urgency and type of surgery, nature and severity of concomitant pathology. To establish the diagnosis of PSC, the diagnostic criteria for the standard definition of cases of infections associated with the provision of medical care were used.

Results. The appointment of empirical AMT in conditions of growing antibiotic resistance of microorganisms that cause PSC in patients with colorectal surgery is a difficult task. In a retrospective analysis of case histories, there are often cases of the use of antibiotics, to which the microorganisms that caused infectious complications are resistant. Given that the results of bacteriological cultures come with a significant delay, sometimes after the patient is discharged from the hospital, these cases remain not fully disclosed.

After the organization of the rational use of antimicrobial drugs (AMD) in the prevention and treatment of PSC in colorectal surgery, a significant decrease in the use of antibiotics has been achieved. The dynamics of AMD consumption is presented in Table 2.

Table 2

Dynamics of consumption of antibiotics in patients with colorectal surgery

\begin{tabular}{|l|l|l|l|}
\hline Indicators & I group & II group & P-value \\
\hline $\begin{array}{l}\text { Duration of ABP, } \\
\text { days }\end{array}$ & $5,3 \pm 2,7$ & $2,3 \pm 1,7$ & $<0,001$ \\
\hline $\begin{array}{l}\text { Duration of AMT, } \\
\text { days }\end{array}$ & $14,3 \pm 11,56$ & $14,1 \pm 8,98$ & 0,895 \\
\hline $\begin{array}{l}\text { Total consumption of } \\
\text { AMT, DDD }\end{array}$ & 1318 & 925 & - \\
\hline $\begin{array}{l}\text { AMD consumption } \\
\text { for 1 patient, DDD }\end{array}$ & 17,2 & 11,9 & - \\
\hline
\end{tabular}

Note: ABP - antibiotic prophylaxis, AMT - antimicrobial therapy, AMD - antimicrobial drugs, DDD - Defined Daily Dose.

The duration of ABP significantly decreased, on average, from $5.3 \pm 2.7$ to $2.3 \pm 1.7$ days, $p$ $<0.001$, while the duration of the AMT course did not undergo significant changes. The total consumption of AMP decreased 1.5 times, from 1318 DDD to 925 DDD, and the average consumption per patient from 17.2 DDD to 11.9 DDD. 
A reduction in the duration of perioperative $\mathrm{ABP}$ did not naturally affect the incidence of postoperative PSC (Table 3).

Table 3.

Characteristics of septic complications in patients with colorectal surgery

\begin{tabular}{|c|c|c|c|}
\hline Complications, $\mathrm{n}(\%)$ & $\mathrm{I}(\mathrm{n}=65)$ & $\mathrm{II}(\mathrm{n}=70)$ & P-value \\
\hline Superficial SSI & $8(12,3 \%)$ & $11(15,7 \%)$ & 0.554 \\
\hline SSI of area/organ & $9(13,8 \%)$ & $10(14,3 \%)$ & 0.570 \\
\hline Pneumonia & $3(4,6 \%)$ & $3(4,3 \%)$ & 0.999 \\
\hline $\begin{array}{c}\text { Catheter-associated } \\
\text { bloodstream inf }\end{array}$ & $4(6,2 \%)$ & $6(8,6 \%)$ & 0.524 \\
\hline $\begin{array}{c}\text { Antibiotic-associated } \\
\text { diarhea }\end{array}$ & $5(7,7 \%)$ & $1(1,4 \%)$ & 0.492 \\
\hline orhers & 0 & $2(2,9 \%)$ & 0.554 \\
\hline $\begin{array}{c}\text { Total of } \\
\text { complications }\end{array}$ & $29(44,6 \%)$ & $33(47,2 \%)$ & 0,999 \\
\hline
\end{tabular}

Note. SSI-surgical site infection, CAIC- catheter-associated bloodstream infection, AADantibiotic-associated diarrhea.

Complications were detected in 29 (44.6\%) patients in group I and $33(47.2 \%)$ patients in group II, $p=0.337$. When analyzing the structure of PSC, there was a slight increase in the number of superficial SSIs $(12.3 \%$ - in group I and $15.7 \%$ - in group II, $p=0.554)$ and SSI of the region / organ $(13.8 \%$ - in group I and $14,3 \%$ - in group II, $p=0.570)$ in the main group, which is explained by stricter control over the detection and registration of these complications in the intervention period. When comparing the total number and structure of PSC, no significant differences were found ( $44.6 \%$ and $47.2 \%$ in groups I and II, $p=0.999)$.

As a result of a decrease in AMP consumption, a statistically significant reduction in the number of AAD cases was achieved from $5(7.7 \%)$ in group I to 0 in group II, $p=0.492$. The etiological structure of infections and the level of resistance of microorganisms to antibiotics were determined on the basis of processing data on 119 strains obtained from surgical patients with coloproctological profile during the development of PSC: 51 strains were obtained from patients in group I and 68 strains from patients in group II.

Analysis of the etiology of PSC pathogens in patients with colorectal surgey showed that in the pre-intervention period the Gram-negative microbiota played the leading role, the total share was $66.7 \%$, in the intervention period its share decreased slightly and amounted to $52.9 \%$. The increased role of gram-positive microorganisms in group B may be associated with a slight increase in the number of wound infections during the intervention period. The etiological structure of five dominant microorganisms - causative agents of infections in surgical patients with colorectal surgery profile is shown in Fig. 1

Figure 1. Etiological structure of infections in colorectal surgery 


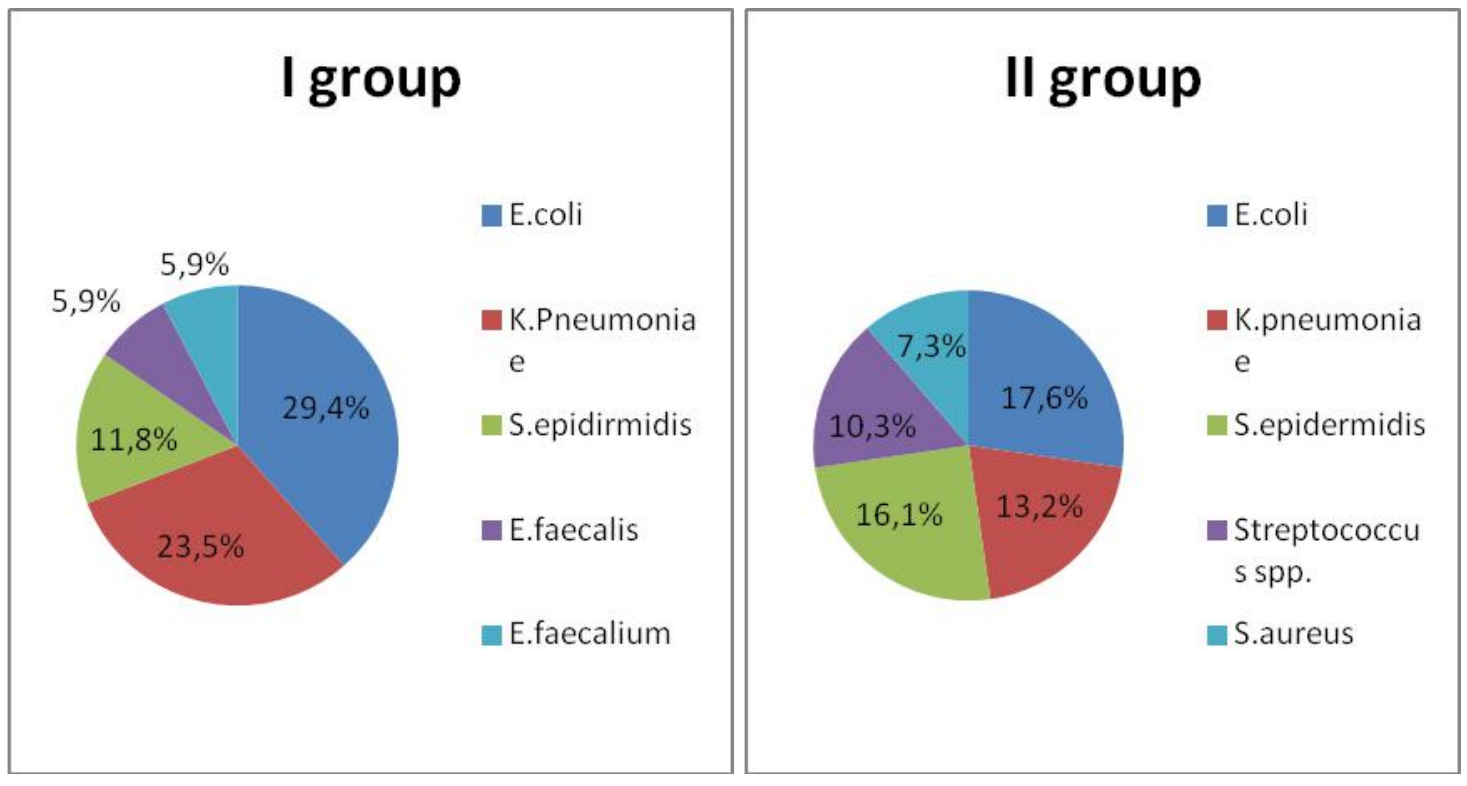

The dominant microorganism in both groups was E.coli $(29.4 \%$ and $17.6 \%$ in groups I and II, respectively, $p=0.184)$. The second place was occupied by another representative of enterobacteria - K. pneumoniae, its share decreased from $23.5 \%$ to $13.2 \%, p=0.224$. In group II, the proportion of typical pathogens of superficial SSI increased, such as St.epidermidis from $11.8 \%$ to $16.1 \%, \mathrm{p}=0.602$, and Staphylococcus aureus from $1.7 \%$ $7.3 \%, p=0.236$, which is associated with an increase in the detection rate of superficial SSI and the frequency of wound cultures.

Table 4 shows the distribution of microorganisms causing PSC in patients with colorectal surgery, according to the degree of resistance to antimicrobial drugs. Rational use of AMP in the intervention period led to a statistically significant decrease in the number of infections caused by ABR strains from $84.3 \%$ to $50.0 \%, \mathrm{p}<0.001$.

The decrease in the level of antibiotic resistance was mainly due to a significant decrease in the number of MDR strains from $70.6 \%$ in group A to $44.1 \%$ in group $B, p=0.005$. The number of infections caused by MDR strains did not differ significantly $(13.7 \%$ and $5.9 \%$ in groups A and $\mathrm{B}$, respectively, $\mathrm{p}=0.202$ ). No panresistant microorganisms were found in both groups.

Table 4.

Characteristics of antibiotic resistance of infectious agents in surgical coloproctology

\begin{tabular}{|l|c|c|c|}
\hline Microorganisms, $\mathrm{n}(\%)$ & Group I $(\mathrm{n}=65)$ & Group II $(\mathrm{n}=70)$ & \\
\hline Sensetive strains (S) & $10(15,4)$ & $35(50)$ & 0,001 \\
\hline $\begin{array}{l}\text { Multidrug resistant } \\
\text { strains (MDR) }\end{array}$ & $41(63)$ & $29(41,4)$ & 0,005 \\
\hline $\begin{array}{l}\text { Extremely resistant } \\
\text { strains (XDR) }\end{array}$ & $5(7,7)$ & $5(7,1)$ & 0,999 \\
\hline $\begin{array}{l}\text { Pandrug } \\
\text { resistant(PDR) }\end{array}$ & 0 & 0 & $<0,001$ \\
\hline Total resistant strains & $46(70,7)$ & $34(48,5)$ & \\
\hline
\end{tabular}

Note. S - susceptible, sensetive strains, MDR - Multidrug Resistance, XDR - Extensive Drug Resistance, PDR - Pandrug Resistance.

Discussion. Mortality from colorectal surgery used to exceed $10 \%$ before the advent of new surgical techniques, mechanical colon cleansing, and better patientcare including the use of antibiotic prophylaxis.Sepsis was the most common cause of death after surgery. Despite the 
marked decrease in mortality rates after colorectal surgery, infectious complications result in significant morbidity leading to increased costs and hospital stay. The most common infectious complications occurring after colorectal surgery include surgical wound infection,abdominal and pelvic abscesses, and the development of anastomotic leaks. The main organisms involved in the pathophysiology of these complications are the colonic flora, mostly anaerobic bacteria including Bacteroides and Clostridia species, and aerobic organisms (E. coli,Proteus,Klebsiella and Pseudomonas species).The use of antibiotic has been shown to significantly reduce the incidence of such complications. Indeed, al-most $40 \%$ of patients would develop wound infection after colorectal surgery if deprived from prophylaxis. The risk drops to $11-22 \%$ with the use of antibiotics.

Conclusion. The introduction of strict control of compliance with the ABP protocols and empirical AMT at the level of a separate surgical unit in a multidisciplinary hospital improves conditions for the rational use of AMD: to reduce excessive antibacterial pressure due to a significant reduction in AMP consumption at the level of the surgical department, which, in turn, naturally leads to a decrease in the proportion of infections caused by ABR strains and creates favorable conditions for increasing the effectiveness of subsequent treatment of PSC in surgical patients with coloproctological profile.

\section{REFERENCES}

1. Aberg C, Thore M. Single versus triple dose antimicrobialprophylaxis in elective abdominal surgery and the impact onbacterial ecology.J Hosp Infect1991;18:149e54.6.

2. Brachman PS, Dan BB, Haley RW, Hooton TM, Garner JS,Allen JR. Nosocomial surgical infections: incidence andcost.Surg Clin North Am1980;60:15e25.

3. Boucher HW, Talbot GH, Bradley JS, Edwards JE, et al. Bad bugs, no drugs: no ESKAPE! An update from the Infectious Diseases Society of America. Clin Infect Dis. 2009; 48:1-12. doi: 10.1086/595011.

4. Carr ND, Hobbiss J, Cade D, Schofield PF. Metronidazole inthe prevention of wound sepsis after elective colorectalsurgery.J R Coll Surg Edinb1984;29:139e42.7.

5. Gul YA, Lian LH, Jabar FM, Moissinac K. Antibiotic prophylaxisin elective colorectal surgery.ANZ J Surg2002;72:275e8.

6. Hennessey DB, Burke JP, Ni-Dhonochu T, Shields C et al. Risk factors for surgical site infection following colorectal resection: a multi-institutional study. Int $\mathbf{J}$ Colorectal Dis. 2016;31(2): 267-71. doi: 10.1007/s00384-015-2413-5.

7. Morris M.S., Graham L.A., Chu D.I. et al. Oral Antibiotic bowel preparation significantly reduces surgical site infection rates and readmission rates in elective colorectal surgery. Ann Surg. 2015;261(6):1034-1040. DOI: 10.1097/SLA.0000000000001125.

8. Ripolles-Melchor J, Ramirez-Rodriguez JM, Casans-Frances R at al. Association Between Use of Enhanced Recovery After Surgery Protocol and Postoperative Complications in Colorectal Surgery: The Postoperative Outcomes Within Enhanced Recovery After Surgery Protocol (POWER) Study. JAMA Surg. Published online May 8, 2019. doi:10.1001/jamasurg.2019.0995.

9. Tackling drug-resistant infections globally: final report and recommendations. The review on antimicrobial resistance 2016. Mode of access:https://amrreview.org/sites/default/files/160518_ Final\%20paper_with\%20cover.pdf. Date of access: May 2016.

10. Wasey N, Baughan J, de Gara CJ. Prophylaxis in electivecolorectal surgery: the cost of ignoring the evidence.Can JSurg2003;46:279e84. 